\title{
Antropogeografia de los degenerados: una mirada foucaultiana de los sistemas espaciales de clasificación
}

\author{
Anthropogeography of the degenerates: \\ a foucaultianian view of space systems of classification
}

Juan Carlos Alegria M.

Manuel Fernando Arce B.

Licenciados en Ciencias Sociales, Universidad del Valle

\section{Resumen}

Desde hace ya mucho tiempo se ha pretendido hacer una historia general y única, capás de abarcar todo bajo un mismo cielo: la política, la economía, las costumbres, etc., y sin embargo el resultado no es otro que decenas de relatos desarticulados y descoloridos en el que las conexiones no son más que temáticas, pues los sistemas de orden, los discursos de verdad, las tecnologías de control y disciplinamiento, la máquina de represión y clasificación sólo se da como vaga representación lejana, misteriosa y abstracta.

Ciertamente desde la época de los cronistas (siglos XVI y XVII) hasta los botánicos de fines del siglo XVIII y desde estos hasta el posicionamiento de las ciencias positivistas en las postrimerías del siglo decimonónico y en nuestra experiencia actual, la historia ha sido abatida por dos sistemas de orden y clasificación: el primero dual, el de seres organizados y no organizados, el segundo en cambio caracterizado por la noción de la vida, en cuyas entrañas han surgido un sinnúmero de prácticas positivas y positivistas que intentan definir y controlar al hombre. En tal sentido debe decirse que el supuesto folclor popular base de "nuestra nacionalidad" reconstruido por los costumbristas y geógrafos de mediados del siglo XIX y retomados por los folcloristas y pedagogos del XX, no han surgido como resultado simplemente de conocer al "pueblo colombiano", sino como parte de ese gran aparato biopolítico, bioético y georacista en las puertas del nacimiento del Estado Nacional. 
Palabras clave: Antropogeográfia, apestados, ciencia del orden, civilización, clasificar, climas, etnografia, herbario universal, higiene pública, los degenerados, región, taxonomia, teoría de las razas, vicios.

\section{Abstract}

For a long time, it has been intended to do a general and unique history, capable of including everything under the same sky: politics, economy, customs, and so on. Nevertheless, the result is not other one that dozens of incoherent and dull accounts with some subject matter connections; since systems of order, discourses of truth, control and discipline-oriented technologies, repression and classification machine are only given as a vague, distant, mysterious and abstract representation. It is true that from the epoch of the chroniclers (16th and 17th centuries) up to the botanists at the end of 18 th century, and from the latter up to the positioning of positivist sciences in the twilights of the 19th century, and in our current experience, the history has been discouraged by two systems of order and classification: the first one, dual, that of organized and not organized beings, the second one, on the contrary, characterized by the notion of life, inside which an unlimited positive and positivist practices have arisen, that try to define and to control the man. To this respect it must be said that the supposed popular folklore, the base of "our nationality", reconstructed by costumbristas (the authors of novels of manners) and geographers of middle of the 19th century, and recaptured by the folklorists and pedagogists of the 20th, has not arisen like a result of simply knowing the "Colombian nation", but as a part of this great georacial, bioethical and biopolitical machine at birth's door of the National State.

Key words: Anthropogeography, stinkers, science of the order, civilization, climates, ethnography, universal herbarium, public hygiene, the degenerates, region, taxonomy, theory of races, vice.

Hacia los umbrales de la época barroca colonial las carabelas danzantes intentarán dar por última vez unos tantos pasos en torno a la candente mesa circular de los pecados. En el centro de la rueda el ojo divino ensangrentado que todo lo ve y que recuerda que el reloj de la vida se 
termina muy pronto, $\mathrm{y}$ alrededor de los vicios: la lujuria y la gula, pareja maestra en esta portentosa tabla de la naturaleza fiera, y a su lado la pereza, madre de todos los vicios humanos. Tal como lo vemos en el Políptico de Tepotzoflán, en Zacatecas (México, 1792) y en los cientos de publicaciones, desde las colecciones barrocas españolas de autos, falsas y coloquios historiales, los teatros medievale ${ }^{2}$ hasta la literatura piadosa de la época colonial más cercana a nuestra experiencia: Pintese la muerte de Ripalda y Astete, ${ }^{3}$ Luz a los vivos y encarmiento de los muertos de Juan de Palafox y Mendoza ${ }^{4}$, El desierto prodigioso de Domínguez Camargo $^{5}$ o Mi vida de la madre de Castillo ${ }^{6}$.

Toda una analítica de la muerte que va de la plástica a la letra escrita y retorna, ha sido una de las grandes obsesiones occidentales, sin embargo tal experiencia de la muerte y su reflejo en la vida viciada del hombre ha recorrido dos senderos diferentes. El primero amarrado a los pecados capitales y a los discursos juridicos, se encadena hacia fines del siglo XVIII a los sendos mecanismos de control y de represión, a la dinámica de los excluidos, en tal sentido deben estudiarse las legislaciones coloniales y republicanas sobre vagancia y mendicidad, el hospital general y centros de reclusión, de los límites barrocos y que a lo largo del siglo decimonónico se irán especializando creando rostros tan fantásticos como el del individuo peligroso, el vagabundo profesional y el revolucionario, pero también las grandes colonias penales y agrícolas, cementerios de los cuerpos desarraigados y degenerados rumbo al exilio, en cuyos espacios encontramos miradas tan distantes como la del leproso, el apestado, el niño que no acata a sus tutores, el criminal, el adúltero o la prostituta y que bajo el viejo juego de analogías y la nueva mecánica de control instaurada bajo el mito republicano, se convertirán con los padres y madres de las regiones progresistas del país, como pioneros de la cultura de vertiente. 16.

Sebastián, Santiago. Contrarreforma y Barroco. Alianza editores, Madrid, 1989, pp. 15 -

${ }^{2}$ Ver por ejemplo: Colecciones de autos y falsas historiales: Adán, Cain y Abel, depositario de la momia; Rey Nabuconosor, degollamiento de San Juan; La danza de la muerte de Juan de Pedraza, o la corte de la muerte de Micael de Carvajal.

Martinez de Ripalda, Jerónimo y Astete, Gaspar. Catecismos de los padres. Madrid. Adm. Real, 1800 p. 152.

4 Palafox y Mendoza. Juan de. Luz a los muertos y encarmiento a los vivos. Imprenta de Gabriel Ramirez. Santa fe de Bogotá, 1762.

${ }^{3}$ De Solis y Valenzuela, Pedro. El desierto prodigioso. Bogotá, 1977. Instituto Caro y Cuervo.

${ }^{6}$ De Castillo, Francisca. Mi vida. Biblioteca popular de cultura. Bogotá. Imprenta Nacional, 1942, p. 226. 
El otro discurso de verdad, en cambio, surge como una mecánica de control, no de los cuerpos sino de los espacios geográficos, toda una dialéctica que intentará ordenar la naturaleza déspota e infame, son los tiempos de la botánica americana, se trata de un análisis de la geografia, la etnografia y la higiene pública no sólo como saberes hegemónicos dados en determinados períodos, sino como espacios discontinuos y contradictorios que han servido para ordenar y clasificar la naturaleza y la naturaleza humana, y en cuyas entrañas se han parido los degenerado bajo el nuevo discurso de las razas dadas hacia finales del siglo de los infames, del siglo XIX. Ambos discursos analizados en la historia de los degenerados en la época republicana ${ }^{7}$, en estas breves líneas retomaremos la segunda mirada.

Ciertamente, a lo largo del período colonial observar ha significado simplemente mirar, contar paso a paso lo que se ha visto, desde el cronista y cosmógono hasta el escribano y corresponsal real, desde los gigantes de Vespucio, los patagones de Fernando de Magallanes, los trigones, polifemos, amazonas y las bestias mulicefalas de Pedro Mártir, Fernández de Oviedo, Simón o Zárate hasta las cartas de Moreno y Escandòn. La letra escrita ha sido fiel copia de la verdad, en la que espejo y reflejo ha ocupado un mismo lugar. La función del cronista colonial consistía, diría Foucault como el caballero de la triste figura, en encontrar una correspondencia entre el mundo real, éste es el Nuevo Continente con los vejuscos textos ya escritos. En ese Universo ha sido permitida la fabulación de centenas de monstruos y criaturas que combinaban los cuatro reinos naturales bajo un solo devenir, bestias a la vez humanoides, árboles monstruosos y animales fabulosos, peces voladores, cucarachas gigantescas, bailarinas y seres hombre orejones con un ojo en la frente que vivían bajo el agua. Pero para el Jardinero de la época del Herbario Universal la letra candente sobre la roca ha dejado de contener la verdad, dirá Caldas "La escritura no se refiere a la creación felicidad original del hombre, la corrección de su posterioridad" (El dilisvium) ${ }^{8}$ ha puesto fin a la Santa Alianza, ser científico en los límites del siglo XVIII ha significado ante todo, ser observador, ser botánico, ordenar, clasificar, jerarquizar, catalogar, no contar ni referirse a viejos autores.

Alegria Montaño, Juan Carlos y Arce Bejarano, Manuel Fernando. Historia de los degenerados en la época republicana.Tesis de grado, Licenciatura en Ciencias sociales. Universidad del Valle, Cali, 2007.

${ }^{8}$ Caldas, Francisco José,. Obras completas. Ed. Universidad Nacional, Bogotá, 1967. p. 11.

\section{Universidad del Valle}


La historia entonces, se ha separado de la ciencia, ya que esta primera, la "historia profana, dice un sabio, no cuenta sino fábulas, o a lo menos hechos confusos o medio olvidados"'. Si el cronista del siglo XVI o XVII trazaba la ruta clásica en el nuevo espacio geográfico, el sabio del siglo XVIII, organiza las cosas creadas por Dios, a través de un lenguaje nuevo en el que el nombre de la cosa representa la cosa misma.

Y sin embargo hacia el final del barroco colonial dos cosas deben decirse, por un lado, todavía la organización de los seres que pueblan la naturaleza, estarán dispersos, otros que deambulan al libre tránsito de la cosmología, y por otro lado, entre el mundo de las identidades y de las diferencias, se posarán infinidad de cuerpos que "encadenados" en el Herbario Universal, se acoplarán con los liquenes, las angiospermas, los arbustos. Lo que siempre ocupó el itinerario de la mathesis universal y que hace parte de la esfera celeste; que "desordenados" grupos humanos, animales y las plantas vegetarán en un espacio único, idéntico para todos, amorfo indeterminado, homogéneo; que agrupados serán parte por derecho, derecho de conquista de la corona. Los signos que señalaban las características de ese espacio - cuerpo, sin forma, será objeto de un apriori histórico; poner los seres que lo pueblan, en cuadriculas; empezará a fraccionarse, a subdividirse y no cesará aún ese itinerario perverso de la naturaleza clasificatoria a asignar un signo a todo lo que nuestra representación puede darnos, es decir, percepciones, pensamientos, etc., signos que deben valer como caracteres y articulan los unos a los otros: "concluimos que las plantas se han esparcido sobre la superficie de los Andes, sin designio, y que la confusión y el desorden reinan por todas partes. Pero no juzguemos de la naturaleza por las primeras impresiones: desconfiemos de las apariencias; no calumniemos antes de penetrar en su santuario augusto; acerquémonos, observamos, midamos antes de decidir sobre materia tan importante". ${ }^{10}$

Este espacio habitado constituido como un gran cuerpo de muchos brazos, anónimo, muchas formas y geoformas, se fraccionará hacia el final del barroco colonial, en un cuerpo definido que va a adquirir ya no la estructura de un cuerpo moldeable por los designios de Dios. Será el carácter sobresaliente, el que determinará el grado y la clasificación en familias, grupos, especies, en fin; sin embargo, no sólo será la tempera-

\footnotetext{
'Ibid, p. 11.

${ }^{10}$ Op. Cit. p, 102.
} 
tura, bien sea fría o caliente; es la observación detallada y minuciosa, en cuyo juego del pensamiento, ya no es leer la marca visible, es buscar en esas regiones ocultas la marca invisible que describirá la época republicana y en cuyos comienzos, se establecerá la excisión de lo sano y lo malsano, es de esa manera cuando Caldas nos dice: "Más lo que deba fijar nuestra atención no son las impresiones exteriores, ni los matices de los colores en su pelo, son si los hábitos internos los que constituyen el carácter esencial y distintivo de su especie. La fuerza, el valor, la rabia, la sangre y la carnicería parece que son las dotes de los que viven en la zona ardiente. Estas terribles cualidades se disminuyen con el calor, se templan y se equilibran con el clima" ". Del temor de una naturaleza "maléfica" que en cualquier momento, sitiará villas y cantones anunciarán el alumbramiento de zonas enfermas y no aptas para la civilización. Es el clima que moldeará sus frutos, las costumbres, "los vicios" como portadores de enfermedades. Y con ellas llegará del inframundo cercando los valles profundos, ciénagas y donde se aparean los mosquitos e infestando. Será entonces, la enfermedad el objeto más importante en la lista del botánico, que viajará por el aire en medio del calor abrasador transportando sus estragos. Naturaleza de la enfermedad "positiva" que redescubre al individuo como ser olvidado con sus signos patológi$\cos$, pero es a través de la enfermedad que la muerte se reviste, se mimetiza entre las calenturas biliosas, las pestes virulentas.

Ahora, la mirada se dedicará a lo que se ve y el verbo a pronunciar su significado. Significante y significado no se acoplarán más en un solo espacio, su separación, permitirá que Humboldt, en 1801 comparare los sistemas circulatorios de bestias de sangre fría y sangre caliente, el sistema gástrico de un animal; si es coextensivo con su capacidad y voracidad y crueldad; clasificarlos en espacios y compartimientos sanos y su opuesto, de la misma manera, los seres que lo pueblan ${ }^{12}$.

Dialéctica de la clasificación y la distribución de la población, en sociedades cultas e incultas, seres simpáticos y antipáticos, contra el amontonamiento, la hediondez y la podredumbre, contra las llagas exhibidas de los leprosos, de los elefanciacos, los apestados, es por eso que una "medida eficaz contra la peste consiste en apartar al enfermo a un despoblado vigilado por una enfermera y un centinela que evitará la

"Ibid. p. 102.

${ }^{12}$ Humboldt, Alexander. Diario / y II, (1803). Humboldt in Kolumbien. Akademie de Wissens Chanterder DDR. Bogotá, 1982, p. 239. 
huida del apestado y su enfermera"13, modelo de inclusión puesto en marcha a través de una nueva mecánica de la clasificación, panorámica y detallada sobre el espacio generalizado. Se abre entonces, una conciencia social; una geopolítica. Conciencia que amenazará no sólo al apestado como en otrora, como raíz del mal, es la patologización de la enfermedad, la cual conllevó a realizar un control estadístico de la salud, las Juntas de Sanidad, es decir, será la máquina - función - totalidad, donde la localización establece relaciones entre la tierra y los seres que la habitan. No obstante, aún hoy se relaciona una determinación geográfica; el clima, las alturas, la vegetación. Caldas, mide, calcula, cree calcular el grado de salubridad del Valle del Patía, del Valle del Cauca, de las llanuras orientales, que según él, son lugares sepulcrales. Diferenciación de zonas aptas y no, método que media centuria después servirá para tecnologizar al hombre a través de unas ciencias humanas; para modelarlo, ajustarlo a los intereses económicos de la sociedad. Buscar los signos taxonómicos, el hombres, sus hábitos y sus contextos, los gestos, los rostros de acuerdo a la similitud de los caracteres, clasificarlos en: sociedades cultas, e incultas, bárbaras y civilizadas, industriosos y perezosos, lujuriosos y abnegados; que modelados por el clima que con sus poderes aceleran el desarrollo o lo retraen, fortalecen o debilitan los cuerpos; es el medio quien los domina "se puede pues decir, que se observa y se toca el influjo del clima sobre la constitución y sobre la moral del hombre"14. Es el medio que modela el cuerpo y destino de la sociedad, son las aguas contaminadas las que producen poblaciones de insensatos e idiotas. Es entonces, el nacimiento de la sociedad como teoría política y los que están por fuera de ella o del pacto colectivo serán señalados como partes de un engranaje dañado, es de esa forma como se tacha al vago, al delincuente, al enajenado mental.

En la época republicana con trascendentalismos como sintesis del devenir, ya no será posible distinguir los seres que pueblan la naturaleza, no como sustancias, sino como fenómenos; los seres se apartarán en singularidades objetivas, es más, la apertura del hombre que se sujetará a la disposición del trabajo, a vivir en sociedad; en el tránsito del Estado al individuo, de estos a los colectivos humanos, modelados por la influencia del clima, de las altitudes; cuerpo roturado por el implacable

"Ibid., Caldas f., p. 119.

${ }^{14}$ Ibid., p. 105. 
calor o el frío que entumece los huesos. Más, es el Estado republicano que requiere de la existencia humana como finitud natural del Estado y del hombre.

Las expediciones corográficas han establecido un antecedente en la historia colombiana, su real interés no sólo radica en las riquezas naturales del territorio. Ha sido un espacio recorrido mirando la riqueza también humana; las expediciones a lo largo y ancho de estas tierras han mostrado rostros ajenos a un proyecto estatal, en el que el espacio al ser un lugar de sintesis, también es un lugar biopolítico aprovechable; bioeconómico para sus posteriores proyectos expansionistas. A través de la antropología, el cuerpo - espacio se distinguirá, como una parte sincronizada a un todo Estado.

La historia se hermanará a través de una antropogeografia que determina los caracteres regionales, las influencias climáticas, los posibles vicios y desavenencias, es cuando el indio, el negro, el mestizo, el zambo, en fin, el hombre comienza a hacer parte de la historia por sus funciones y cualidades, miradas bajo un solo estándar; en sí, en las divisiones político administrativas, configurando unos ejes de poder muy bien marcados, para situar un ejemplo, el gran Cauca es desmembrado. No obstante, ya no será sólo la relación clima-trabajo las causantes de la despoblación, se agrega a esa dupla un aditamento más, la enfermedad, no vista desde la naturaleza - cuerpo, sino desde la sociedad - cuerpo caracterizadas por las enfermedades humanas, es por ello, que toma fuerza una bioética laboral, cultural a través de una eugenesia: robustez - debilidad, bárbaro - salvaje, asocial y ciudadano, sociedades taradas y sociedades del "bueno tono", determinaciones antagónicas, aunque, hoy el estofado simula la risa irónica de la clasificación, de esos espacios, esos cuerpos, de esas regiones "abnegadizas", pobres y al margen de ciertos ejes de poder político.

Esta ciencia del orden ha permitido gracias a los tallos y flores del Jardinero reemplazar el viejo teatro eclesiástico de las analogías y semejanzas duplicadas por un sistema de signos, una ciencia cualitativa y algebraica, un sistema ante todo taxonómico, en el que la geografía es al sistema de orden, lo que la semiología es frente a la historia.

Las plantas se clasifican en género, especie, familia, orden; el nombre específico indica la particularidad de la especie: piloso, la planta: repens (rastrera), purgans (purgante), nombre del género descriptivo: 
vilucus (tuberosus), la vellosidad del ginostemo de la especie Telipogan angustifolius, el nombre geográfico donde se localiza: pasiflora Antiochensis, el nombre propio del botánico: Caldasia, Mutisia, Posadea, Restrepia, Maiz Zea, o el carácter sobresaliente y particularidad del fruto: Copuliferas, o flor: Inflorescencias, los híbridos separados por el progenitor: divital amarilla $\mathrm{x}$ roja. Un sistema ciertamente estructural que permite transcribir lo visible al lenguaje, sistema óptico que permite clasificar el reino planta - hombre: de India y español nace mestiza; de mestiza y español nace castiza; de albino y español torna atrás; de loba e india, zambayo; de chamizo y mestizo nace coyote, de tente en el aire y mulata, nace no te entiendo... De Mutis y Humboldt a Caldas y Zea, la teoría del signo ha permitido distribuir la forma y la magnitud relativa, ir de la naturaleza déspota a la localización detallada y descriptiva.

Sin embargo, podría parecer que el centro del debate de los umbrales del barroco colonial son las plantas, en realidad éstas tan sólo sirven de analogías al cuerpo humano, dirá Arboleda "Dios que cuidó de dar leyes a toda la creación física, hasta los miserables insectos, no olvidó seguramente, la noble descendencia del infeliz Adán..."15, pues así como las abejas son indivisibles para la abeja misma, el hombre lo es para él, las plantas nos prestan sus órganos, sus hojas, raíces, sus pistilos y penes, su útero y flores. Asi que naturaleza y naturaleza humana se prestan bajo este sistema de orden estructural, un imaginario sobre cuyos cimientos ha sido posible crear las nuevas ciencias espaciales: una antropogeografia, una nueva geografia espacial.

Hacia el corazón del siglo decimonónico las algas, hepáticas, liquenes y musgos del sabio jardinero serán desplazadas por los cuadros costumbristas: Los marraneros de tierra caliente de Espinosa, o el Indio de Búrica de Herry Price, tal nueva temática pictórica dada por el nuevo viajero, el Geógrafo - etnógrafo no surgen en realidad del deseo de conocer al hombre, ni de representar un supuesto folclor popular, de lo que se trata en verdad es de catalogar por segunda vez la naturaleza humana, un discurso evolucionista antes que Darwin, alrededor a las categorías de razas pasivas e inertes, afectas, degradadas, lujuriosas y perezosas. Son los tiempos ya no de los cronistas, ya no del viajero corresponsal real, ya no de los expedicionarios botánicos, sino de las expediciones

\footnotetext{
15 Arboleda, Sergio Gabriel. La república en la América española., Sexto articula, 1869. Biblioteca Popular de Cultura, Bogotá, 1951, p. 148.
} 
corográficas, permanentes y contratadas. Desde Zea y Baptiste Boussingault en las cabeceras ribereñas decimonónicas, pasando por Codazzi, Ancizar y Triana hasta los confines del gabinete de historia natural de los últimos naturalistas de las academias médicas en el amplio espectro del siglo XX, Restauración y Regeneración, degeneración y envilecimiento de los carácter morales serán las columnas de esa nueva teoría de las razas, en torno a la triple funcionalidad: una que va de la pereza al trabajo, la otra de la degeneración y las patologías a la conservación de la vida y, una más de la conducta moral y el pensamiento a la cultura y el lenguaje.

Francisco José de Caldas, en los límites del Herbario Universal, clasificaba la población del reino neogranadino, en aquellos que sirven a las leyes de Dios y el monarca español, y en los que están más allá de los límites de las leyes, los paganos, los bárbaros-salvajes ${ }^{16}$. José María Samper, miembro de la Sociedad Etnográfica y Geográfica de París, la clasificó en 1861 en: Criollo Bogotano, Antioqueño, Blanco, indio, pastuso, indio de la cordillera oriental o chibcha, mulata de la costa Magdalena, llanero de la Orilla del Orinoco, zambo botelero - boga "raza animal", indio pastuso "rechoncho, bestia", negros ${ }^{17}$. Caldas solo emplea dos categorias: seres organizados y no organizados, dos parámetros que no se contraponen como la vida y la muerte, sino que se complementan; Samper en cambio emplea este triángulo epistémico; modelo basado en la capacidad para el trabajo en relación con el espacio geográfico, en sus vestimentas y cotidianidad en relación con su moral, en su taxonomía en combinación con sus patologías. "El Antioqueño es un tipo muy interesante, es el más hermoso... fuerte..."; el indio pastuso en cambio, es un "guerrillero, vascongado, semi-salvaje, de raza primitiva", "el mulato es turbulento porque es mulato, es decir por exhuberancia de savia, de bellas cualidades...", en contraposición al zambo, en el que la "evidente inferioridad de las razas madres (la africana, negra y la indigena cobriza) y su degradación mas o menos profunda, auxiliadas por un clima en que todo fermenta... han producido en el zambo una raza de animales en cuyas formas y facultades la humanidad tiene repugnancia en encontrar su imagen....

16 Op. Cit. Caldas. «Estado de la geografia del virreinato de Santa fe...», p. 187.

${ }^{17}$ Samper, José Maria. Ensayo sobre las revoluciones politicas. Paris, octubre 3 de 1861. Universidad Nacional de Colombia, Bogotá, 1969, pp. 68 - 101. 
Para Caldas, Mutis y Humboldt, así como para Codazzi o Samper, la naturaleza tiene una imagen ciertamente negativa, sólo que en los primeros los males son el resultado de la infame vegetación, del desorden natural que hay que ordenar. El Sabio Jardinero, entonces, no sólo clasifica las cosas sino que patologiza los espacios (que también responden a un orden).

Los climas malsanos, los enjambres de platanales que estancan los aires, las pestilencias de los panteones de Iglesias y cementerios, las miasmas de los pantanos cuyas moléculas nauseabundas viajan con los vientos y degeneran en pestes malolientes, han obligado a la medicalización de los espacios; de ello darán cuenta las tantas medidas que desde las reformas borbónicas y a lo largo de la época republicana se darán; en torno a los vivos y los muertos, retirad los cementerios de la ciudad, enterrad con la suficiente profundidad, vigilad a los apestados, cread policía de higiene y aseo que controle a los malolientes, vagabundos y prostitutas, clasificad los espacios sociales en distintos, barrios y nombrad corregidores, policías, médicos, higienistas de distrito ${ }^{18}$.

Los otros, los médicos - geógrafos del corazón del siglo XIX parten de esta medicalización espacial y geográfica hasta llegar a la patologización del cuerpo. Así las moléculas nauseabundas y podridas, resultantes de los pestilentes aires no sólo viajan por este, penetran por la piel y en las transpiraciones, sino que se deslizan por el sistema circulatorio y digestivo, afectan múltiples órganos vitales, el hígado, el de la generación, el cerebro, produciendo diversos males tantos físicos como morales y políticos, la pereza colectiva, la autoestima baja, la savia exaltada de los boteleros, las deformidades y monstruosidades, los elefancíacos y sifilíticos, los cotudos y carroñosos, los liberales y locos morales, es decir, toda una variedad de males antropogeográficos, antropatológicos y socio-anatómicos asociados a la nueva teoría de las razas y la degeneración, tal como lo sustentaban los médicos - políticos de las raíces del siglo XX en Jerónimo Torres, López de Mesa y Jiménez López. ${ }^{19} \mathrm{Se}$ trata del gran debate sustentado hacia los linderos de los siglos XIX y $\mathrm{XX}$ en torno a la decadencia de "nuestra raza", discurso suscrito a los espacios exteriores, que abarcara todas las miradas, todos los saberes positivistas; desde la geomédica y la antropogeografia hasta la anato-

${ }^{18} \mathrm{Op}$. Cit. Alegria y Arce.

${ }^{19} \mathrm{Ibid}$. 
mopolítica y la literatura. Desde Manuela y María hasta Risaralda y La Vorágine.

Ciertamente, Efraín describe el majestuoso paisaje vallecaucano, con tanta majestuosidad y detalles, las planicies de verdes gramales, regadas de riachuelos. ${ }^{20}$ que contrastan con la imagen que le anteceden. Tanto para el Jardinero de los límites del siglo XVIII como para los geógrafos de la época de Isaacs, la naturaleza mantiene aquella imagen negativa, en la que los climas candentes por el juego de analogías, se asemejan al infierno sólo que ese nuevo sistema de orden ha permitido crear otro lenguaje, no solo más especializado, sino ajeno a la temática del pecado, un lenguaje mejor estructurado que responde y se sustenta en lo real, no en la especulación, pero por ello no deja de fascinar y de ser disparatado.

Aquí el orden equivaldrá al objeto como se estructura en su interior y se percibe en su exterior, en el que lo real, la verdad sólo podrá verse 0 dependerá del lente desprevenido que le mire; solo el espacio de esta burbuja espera el instante de ser enunciada de nuevo.

El sabio Humboldt relacionaba hacia 1801, los valles cerrados, la humedad y concentración del sol de Honda, con los resfrios y fiebres constantes, con los cotudos y monstruosidades de este reino o "tierra de los cotos"21. Isaacs, en su lírica poética, no es que evada un poco más de media centuria después tal lenguaje; lo que pasa es que las malignidades ya no sólo están en los espacios naturales, estas están suscritas a los sociales. La degradación de la naturaleza, es ahora horror de la vida del hombre.

El lenguaje de Isaacs intenta restablecer las viejas semejanzas duplicadas, pegar los filosos restos del espejo roto por el martillo del sabio, al devolver la coherencia entre las vejuscas hojas carcomidas por el tiempo de los empolvados volúmenes sagrados de la biblioteca de Babel con los paisajes del Valle, al retomar la descripción Edénica y primera del mundo con su realidad. Sólo es que esas monstruosidades que le carcomen, lo creado por Dios, estarán contenidas en las vicisitudes sociales, en las contiendas y desplomamiento, los viejos sistemas de producción en los espacios del nuevo mito republicano, Isaacs, lo único que hace es evadir los conflictos de su entorno al situarse tiempo atrás a la ruptura de la Santa Alianza, antes de la tragedia del pecador.

${ }^{20}$ Isaacs, Jorge. Maria. Ed. Norma, Bogotá, 1967, p. II, 14.

${ }^{21} \mathrm{Op}$. Cit. Humboldt, p. 239. 
De Vespucio y Simón a Mutis y Caldas, de estos a Codazzi y Samper, del Cosmógono al Jardinero y de éste al Geógrafo, se ha desplegado todo un juego de devenires, de analogías y semejanzas duplicadas, en el que plástica y lenguaje escrito, significante y significado han dejado de coexistir en un mismo espacio, en el que el orden ha permitido devolver la correspondencia universal, y desde el médico-geógrafo al etnógrafopolítico, desde Samper a López de Mesa, se ha respondido por doble ocasión aquella vejusca pregunta sobre la pereza, ¿Qué hacer con las razas primitivas, los degenerados?

Solución que ha permitido sustentar un sin número de medidas infames como colonias penales, las leyes sobre migración masivas y controladas, la segregación racial por regiones, el oprobio social que por centurias hemos soportado, el capital medicalizado del país, los discursos sobre el trabajo, el ser patriota, la peregrinación perpetua de millares de rostros olvidados y cuerpos sin huellas, cuyas sombras retumban cada vez con más fuerza en nuestra experiencia actual. 
ALEGRIA MONTAÑO, Juan Carlos y ARCE BEJARANO, Manuel Fernando. Historia de los degenerados en la época republicana. Tesis de grado, Licenciatura en Ciencias sociales, Departamento de Geografia-universidad del Valle, Cali, 2007.

ARBOLEDA, Sergio Gabriel. La República en la América Española. Biblioteca Popular de Cultura colombiana. Ed. ABC. Bogotá, 1951, p. 180, O. 152. ASTETE, Gaspar y MARTÍNEZ DE RIPALDA, Jerónimo. Catecismos de los padres de Riparda y Astete Adm. Real. Madrid. 1800, p. 152.

CALDAS, Francisco José de Estudios Varios. Imprenta Nacional, Bogotá, 1941, p. 180.

CALDAS, Francisco José de. Obras Completas. Universidad Nacional, Bogotá, 1967, p. 190.

DE SOLIS Y VALENZUELA, Pedro. El Desierto Prodigioso y Prodigio del desierto. Tomo I. instituto Caro y Cuervo, Bogotá, 1977, p. 210.

DEL CASTILLO, Josefa. Mi vida. Biblioteca Popular de Cultura Colombiana, Imprenta Nacional, Bogotá, 1942, p. 226.

DÍAZ CASTRO, Eugenio. Manuela. Ed. Carvajal, Cali, 1967, p. 412.

FOUCAULT, Michel. «Arqueología del Saber». Ed. Siglo Veintiuno, Mético, 1990 p. 355.

FOUCAULT, Michel. Vigilar y Castigar. Ed. Siglo XXI, México, 1981, p. 314.

FRANCO, Ramón. Angropogeografia colombiana. Imprenta oficial. Manizales, 1941 , p. 368.

HUMBOLDT, Alexander. Alexander Von Humbold in Kolumbien. Diario I y II. Akademie de Wissens chaften der DDR, Bogotá, 1982.

ISAACS, Jorge. La María. Ed. Norma, Bogotá, 1967, p. 492.

MUTIS, José Celestino. Pensamiento científico y filosófico de José Celestino. V. 10, Recopilación de Guillermo Hernández de Alba. Ed. Fondo de Cultura Cafetera, Bogotá, 1982, p. 166.

PALAFOX Y MENDOZA, Juan de. Luz a los Muertos y encamiento a los vivos, imprenta de Gabriel Ramírez. Santafé de Bogotá, 1762.

SEBASTIAN, Santiago. Contrarreforma y Barroco. Alianza Editores. Madrid, 1989 , p. 443.

Recibido: agosto 2007

Aprobado: noviembre 2007 